\title{
QUANTIFYING DISPERSAL AND ESTABLISHMENT LIMITATION IN A POPULATION OF AN EPIPHYTIC LICHEN
}

\author{
Silke Werth, ${ }^{1}$ Helene H. Wagner, Felix Gugerli, Rolf Holderegger, Daniela Csencsics, \\ Jesse M. Kalwis, ${ }^{2}$ and Christoph Scheidegger \\ Section Ecological Genetics, WSL Swiss Federal Research Institute, 8903 Birmensdorf, Switzerland
}

\begin{abstract}
Dispersal is a process critical for the dynamics and persistence of metapopulations, but it is difficult to quantify. It has been suggested that the old-forest lichen Lobaria pulmonaria is limited by insufficient dispersal ability. We analyzed 240 DNA extracts derived from snow samples by a L. pulmonaria-specific real-time PCR (polymerase chain reaction) assay of the ITS (internal transcribed spacer) region allowing for the discrimination among propagules originating from a single, isolated source tree or propagules originating from other locations. Samples that were detected as positives by real-time PCR were additionally genotyped for five L. pulmonaria microsatellite loci. Both molecular approaches demonstrated substantial dispersal from other than local sources. In a landscape approach, we additionally analyzed 240 snow samples with real-time PCR of ITS and detected propagules not only in forests where L. pulmonaria was present, but also in large unforested pasture areas and in forest patches where L. pulmonaria was not found. Monitoring of soredia of L. pulmonaria transplanted to maple bark after two vegetation periods showed high variance in growth among forest stands, but no significant differences among different transplantation treatments. Hence, it is probably not dispersal limitation that hinders colonization in the old-forest lichen L. pulmonaria, but ecological constraints at the stand level that can result in establishment limitation. Our study exemplifies that care has to be taken to adequately separate the effects of dispersal limitation from a limitation of establishment.
\end{abstract}

Key words: dispersal kernel; landscape-scale dispersal; lichenized ascomycetes; real-time PCR; recruitment limitation; snow trap; transplantation.

\section{INTRODUCTION}

Dispersal is a fundamental population process that is of critical importance for the persistence and dynamics of populations (Travis and French 2000, Levin et al. 2003). In community ecology, dispersal (Yu et al. 2004, Ozinga et al. 2005) vs. niche assembly (Gilbert and Lechowicz 2004, Hall et al. 2004, Svenning et al. 2004) of local communities has been under much debate, but it is clear that sufficient dispersal is particularly important for organisms whose habitat exhibits spatiotemporal dynamics and for patch-tracking organisms, such as several epiphytic lichens (Levin 1995, Hanski and Gaggiotti 2004, Snäll et al. 2005a).

The quantification of dispersal is far from trivial (Clobert et al. 2001, Levin et al. 2003). Direct measures of dispersal include the tracking of animal movement by means of direct observation (Belisle and Desrochers

Manuscript received 23 September 2005; revised 26 January 2006; accepted 26 January 2006. Corresponding Editor: N. J. Gotelli.

${ }^{1}$ Present address: Warren Hall 23-163, Department of Ecology and Evolutionary Biology, 900 Veteran Avenue, University of California at Los Angeles, Box 951606, Los Angeles, California 90024 USA. E-mail: werth@ucla.edu

${ }^{2}$ Present address: Department of Entomology, University of Stellenbosch, Private Bag X1, Matieland 7602, South Africa.
2002, Fischer and Lindenmayer 2002), live-trapping in mark-recapture studies, experimental model systems for invertebrates or rodents (Wiens et al. 1993, With et al. 1999, Parker and Mac Nally 2002), radiotelemetry, and GPS tracking (Szacki 1999, Haynes and Cronin 2004). In vascular plants, dispersal can be directly estimated in seed trap experiments (Bullock and Clarke 2000, Nathan et al. 2001). Spores and vegetative propagules of fungi and lichens caught in spore traps often do not allow reliable species identifications. Direct dispersal estimates may nevertheless be obtained in these organisms by analyzing the contents of spore traps using speciesspecific molecular approaches (Walser et al. 2001). Alternatively, single propagules may be marked and their movement tracked, but this is technically difficult and requires large sample sizes (Nathan et al. 2003). Indirect dispersal estimates may be derived from molecular genetic data (Sork et al. 1999, Dyer et al. 2004). In particular, $F_{\mathrm{ST}}$ statistics measuring genetic differentiation of subpopulations relative to a total population have been used to parameterize dispersal (Bohonak 1999, Neigel 2002). Alternatively, statistical modeling is used to estimate dispersal kernels (Snäll et al. 2005b), an approach that has been widely used in metapopulation studies of organisms in fragmented landscapes (Hanski and Gaggiotti 2004). Spatiotemporal dynamic modeling proved helpful in quantifying the 
importance of long-distance dispersal (Bridle et al. 2001, Paradis et al. 2002, Clark et al. 2003, Higgins et al. 2003), contributed to the understanding of the movement of organisms across landscapes (With and Crist 1995, Keitt et al. 1997, With and King 1999, Tischendorf et al. 2003), and predicted the spread of pathogens (Aylor 2003).

The epiphyte Lobaria pulmonaria, a putatively dispersal-limited lichen (Scheidegger 1995, Walser et al. 2001, Walser 2004) that is associated with old-growth forests and with traditional sylvopastoral landscapes in Europe (Rose 1992, Gauslaa and Solhaug 1999, Rolstad et al. 2001), has recently been used as a model organism for patch-tracking metapopulations (Snäll et al. 2005b). Recruitment in lichen populations, i.e., the number of new individuals entering a given population per generation, is a result of two processes. First, dispersal has to be sufficient to provide propagules at a given habitat. Here, we refer to a limited availability of propagules in a given habitat as dispersal limitation (Nathan and Müller-Landau 2000). A second key process determining recruitment at a particular site is the establishment of young individuals. Establishment is influenced not only by abiotic factors such as site conditions, but also by biotic factors like competition. The inability of establishment in a given habitat is, in the following, referred to as establishment limitation (Nathan and Müller-Landau 2000). Dispersal limitation and establishment limitation are not mutually exclusive, but may simultaneously reduce recruitment in a population. A lichen species' sensitivity to disturbances related to forest management may be due to dispersal limitation, establishment limitation, or a combination of both. Walser et al. (2004) argued that a restricted number of different microsatellite multilocus genotypes found in young thalli of $L$. pulmonaria on a tree points towards limited dispersal of vegetative propagules. However, studies investigating already established individuals are not able to separate dispersal from establishment limitation.

We used transplantation experiments and dispersal estimates to separately assess the contributions of establishment limitation and dispersal limitation to overall recruitment in a population of $L$. pulmonaria. A transplantation experiment involving soredia (i.e., vegetative propagules) had the purpose of exploring establishment of L. pulmonaria under different site conditions, while dispersal of L. pulmonaria propagules was quantified both at the local and the landscape scale from the content of snow traps (Walser et al. 2001) using a molecular approach.

\section{Methods \\ Study area}

Our study was located at $46^{\circ} 31^{\prime} \mathrm{N}$ and $06^{\circ} 11^{\prime} \mathrm{E}$ in the northern part of the Parc Jurassien Vaudois in the Swiss Jura Mountains at an elevation of $1400 \mathrm{~m}$. This traditional sylvopastoral landscape consists of wooded pastures and of forests dominated by Norway spruce (Picea abies) on carstic limestone bedrock (Vittoz 1998). Mean annual precipitation and July temperature are $2100 \mathrm{~mm}$ and $10^{\circ} \mathrm{C}$, respectively (Kirchhofer 1995), and the mean annual precipitation of the closest weather station, Le Sentier, is $1679 \mathrm{~mm}$ (Landeshydrologie und -geologie 1992). The most frequent host trees of $L$. pulmonaria were sycamore maple (Acer pseudoplatanus) and beech (Fagus sylvatica), both occurring scattered throughout the study area (Kalwij et al. 2005). Kalwij et al. (2005) mapped 241 plots of 1 ha for trees colonized by L. pulmonaria; a subsample of 17 of these plots with a known spatial distribution of host trees were used for the hypothesis-based sampling employed in our study to quantify local- and landscape-level dispersal of $L$. pulmonaria.

\section{Life cycle of Lobaria pulmonaria}

The haploid fungus $L$. pulmonaria reproduces sexually via ascospores developed in apothecia, a characteristic type of fruiting bodies found in ascomycete fungi. Ascospores contain only the fungus $L$. pulmonaria. However, the lichen is also able to form vegetative diaspores, soredia, which consist of haploid fungal hyphae and green algae. While soredia need to incorporate an appropriate cyanobacterial partner in order to survive and form a thallus, ascospores need to incorporate both suitable green algae and cyanobacteria.

\section{Quantifying dispersal limitation}

Sampling of snow samples.-To quantify dispersal in L. pulmonaria at the landscape level, we randomly collected 240 snow samples in 1-ha plots, adapting the sampling strategy by Scheidegger et al. (2002). In a randomized subsample of the plots investigated by Kalwij et al. (2005), we obtained 10 snow samples in eight plots each from the following two categories (Fig. 1): plots containing more than three L. pulmonaria trees and plots without $L$. pulmonaria. The third category investigated was open pasture. Random coordinates were generated within the land-use type pasture at a minimum distance of $60 \mathrm{~m}$ from the closest forest edge and at $120 \mathrm{~m}$ from the center of the closest open pasture plot. The upper 5-cm layer of snow of an area of $20 \times 50$ $\mathrm{cm}$ was collected in late March 2003 and stored at $-20^{\circ} \mathrm{C}$ to avoid DNA degeneration.

To quantify the dispersal kernel of L. pulmonaria and to estimate anisotropy of dispersal, we also collected 240 snow samples at four directions (north, east, south, west) and six distances ( $1 \mathrm{~m}, 5 \mathrm{~m}, 9 \mathrm{~m}, 20 \mathrm{~m}, 30 \mathrm{~m}, 40 \mathrm{~m})$ from a single isolated sycamore tree containing sorediaproducing L. pulmonaria situated within a spruce forest, collecting 10 samples at each distance and direction. Five buckets per distance and direction were placed so that their opening was level with the snow surface, the other five protruded $15 \mathrm{~cm}$. The source tree was spatially isolated with the two nearest trees containing sorediaproducing L. pulmonaria at distances of $200 \mathrm{~m}$ and 240 


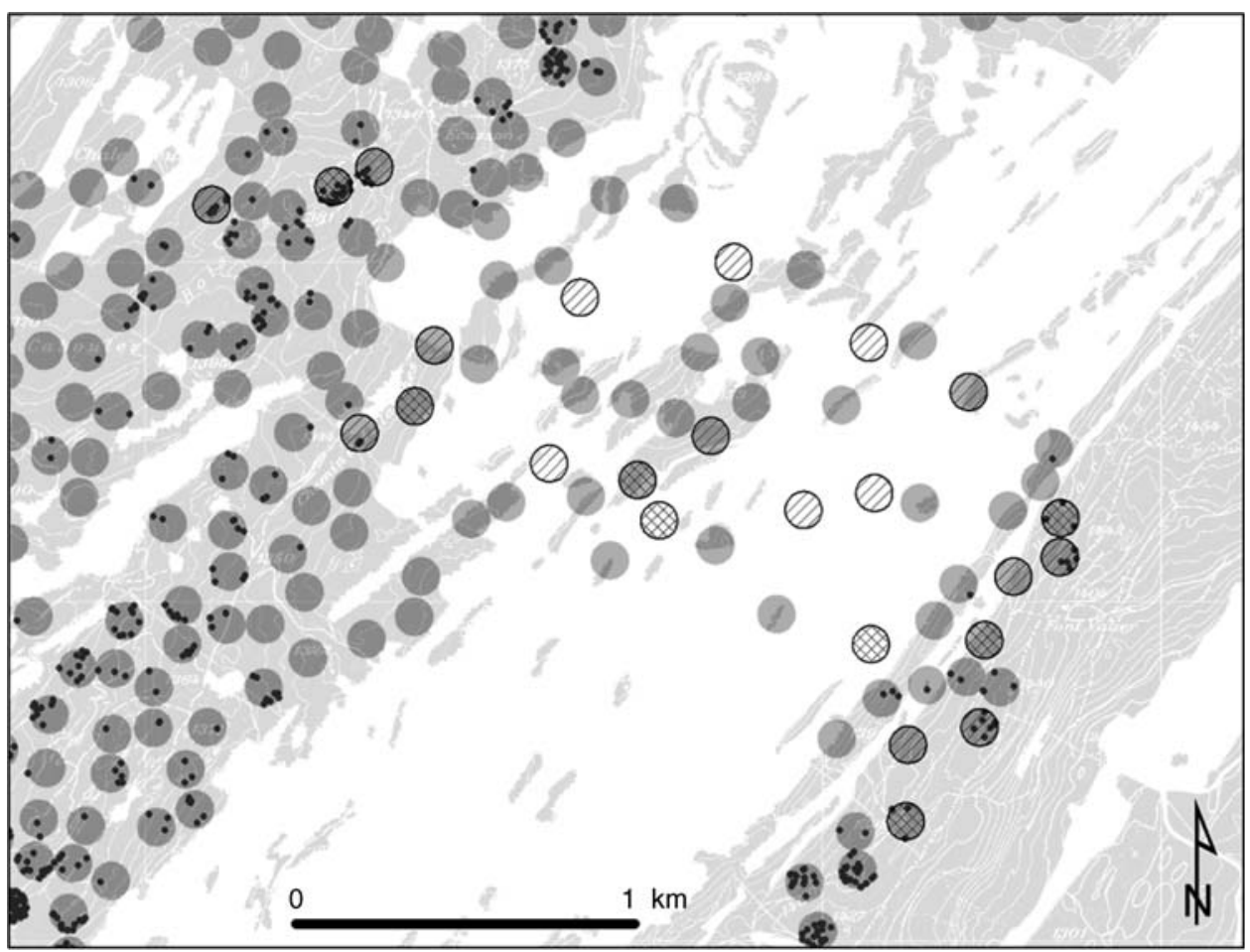

FIG. 1. Results from the landscape approach to studying dispersal in Lobaria pulmonaria in a sylvopastoral landscape in Switzerland: light gray, forest; white, pasture; gray circles, 1-ha plots mapped for L. pulmonaria; black dots, trees carrying $L$. pulmonaria; hatched circles, plots from which 10 snow samples were analyzed; and cross-hatched circles, plots in which snow samples containing L. pulmonaria DNA were found using a real-time PCR assay of ITS (internal transcribed spacer). Note that $L$. pulmonaria was only searched for within the 1-ha plots. (Digital data are from Landeskarte der Schweiz, Bundesamt für Landestopographie, Bern, Switzerland.)

$\mathrm{m}$ in south and north directions. We found no apothecia on L. pulmonaria thalli of the source tree. Previous molecular analyses of all thalli on the isolated sycamore tree showed that they all belonged to the same microsatellite multilocus genotype and ITS (internal transcribed spacer) allele (S. Werth, unpublished data). ITS alleles and microsatellite alleles different from those found on the isolated sycamore tree were thus interpreted as evidence of dispersal of propagules from more distant sources. We additionally genotyped L. pulmonaria from the closest host trees for microsatellites and ITS.

In the experiment, we used buckets with a total volume of $6.4 \mathrm{~L}$ (diameter $21 \mathrm{~cm}$, depth $19.5 \mathrm{~cm}$ ) as snow traps, which exposed a surface of $346 \mathrm{~cm}^{2}$. All traps were coated with plastic bags prior to exposure. Snow traps were exposed for seven days (27 February-6 March 2003) under snowfall conditions, with night temperatures below $0^{\circ} \mathrm{C}$. Snow trap content was collected and stored at $-20^{\circ} \mathrm{C}$ in order to avoid DNA degradation.

To avoid contamination, snow samples were processed in a laboratory where no previous studies on $L$. pulmonaria had been carried out. Prior to and in between filtrations, the filtering equipment was rinsed thoroughly with double-distilled water. The frozen snow samples were thawed and prefiltered to remove large particles through a sieve with a mesh size of $1.5 \mathrm{~mm}$. The liquid phase was then filtered through paper filters using filtering equipment by Nalge (Nalge Company, Rochester, New York, USA). To avoid DNA degeneration, filters with litter from the snow samples were stored at $-20^{\circ} \mathrm{C}$ in sealed sterile petri dishes. We distributed a filtrate over two or more autoclaved and UV-lighted tubes if necessary. For all further procedures until DNA-extraction, we avoided opening the lids in order to prevent cross-contamination. Samples were lyophilized and tubes closed by epoxy resin. Subsequently, samples were pulverized in a mixer mill (Retsch MM 2000, Haan, Germany).

Total genomic DNA was isolated using the DNeasy 96 plant kit (Qiagen, Hilden, Germany) according to the manufacturer's protocol. To avoid cross-contamination among samples, we injected the extraction buffer with sterile injection needles. To ensure that DNA extractions had worked, we included positive controls containing 1 soredium, 3 or 10 soredia, or $50 \mathrm{mg} \mathrm{L}$. pulmonaria thallus. Furthermore, we included negative controls and blind samples. Blind samples were obtained by filtering a snow sample, rinsing the filtering equipment, filtering 1 $\mathrm{L}$ double-distilled water through a fresh filter paper, and scraping paper material from its surface, which was then 
used in DNA extraction, and rinsing the equipment before the next filtering was performed.

Fungal-specific nested PCR (polymerase chain reaction) was performed with ITSIF and ITS4 as external primers following Zoller et al. (1999). Using this PCR product as a template, a $L$. pulmonaria-specific real-time PCR assay allowed the discrimination of two alleles (2 bp insertion/deletion; Zoller et al. 1999). Each 25- $\mu \mathrm{L}$ PCR reaction contained $1 \mu \mathrm{L}$ of genomic DNA, 900 $\mathrm{nmol} / \mathrm{L}$ of each of two new designed primers ITS-516R (5'-AAC CTG CGG AAG GAT CAT TAT- ${ }^{\prime}$ ) and ITS- $137 F$ (sequence 5'-CCA AGC GAA CGT ATT TAC TGC-3'), $50 \mathrm{nmol} / \mathrm{L}$ of each of two new designed TaqMan MGB probes (INDEL1, TG absent, 5'-6FAMACT CGG ACC ACA TGA-3'-MGB; INDEL2, TG present, sequence 5'-VIC-CGG ACC ACA CAT GA-3'MGB; Applied Biosystems, Rotkreuz, Switzerland) and $1 \times$ TaqMan Universal Master Mix (Applied Biosystems). Amplification reactions were performed on an ABI Prism 7700 Sequence Detector (Applied Biosystems) with an initial activation of the polymerase for 120 s at $50^{\circ} \mathrm{C}$, denaturation at $95^{\circ} \mathrm{C}$ for $10 \mathrm{~min}$, and 45 cycles of $95^{\circ} \mathrm{C}$ for $15 \mathrm{~s}$ and $60^{\circ} \mathrm{C}$ for $60 \mathrm{~s}$. The samples were genotyped visually and with the allelic discrimination of the Sequence Detection Systems 1.7 (Applied Biosystems).

Five fungal-specific microsatellite loci, $L P u 03, L P u 09$, LPu15, LPu20, and LPu27 (Walser et al. 2003), were analyzed with five multiplex PCR repetitions each as described in Werth et al. (2006), with the single modification that the amplification included 35 cycles.

To test the sensitivity of the real-time PCR approach with ITS, we used the positive controls, i.e., the DNAextracts of 1,3 , and 10 soredia with 11,12 , and 12 repetitions each. The 35 DNA extracts were genotyped in the real-time PCR approach with three replicate realtime PCR reactions for each extract.

Our initial reason for using real-time PCR was to quantify the amount of diaspores in each bucket. However, the variance in the measured DNA quantity among replicate PCR runs with known numbers of diaspores that were added to snow dust without $L$. pulmonaria was too high to allow for a meaningful quantification. Thus, we used the number of positive samples across the 10 buckets at each distance and direction.

We extracted DNA from 12 common lichen species of the study region (Bryoria fuscescens, Cladonia sp., Hypogymnia physodes, Lecanora albescens, Leptogium saturninum, Melanelia exasperatula, Parmelia sulcata, Physconia distorta, Platismatia glauca, Pseudevernia furfuracea, Usnea hirta, and Xanthoria parietina) and from two species of the genus Lobaria ( $L$. linita, $L$. scrobiculata) to check the $L$. pulmonaria specificity of both the real-time PCR and microsatellite approach. Of the latter two species, only L. scrobiculata is known to occur in the study area, where it has been reported from a single tree.

\section{Quantifying establishment limitation}

Stand and receptor tree selection for transplantations.-The density of large deciduous trees was classified (high, $\geq 4$; low, $<4$ ) using color infrared aerial images of scale 1:10000 taken in August 2000 (Swisstopo, Wabern, Switzerland) on a 100-m grid. Stand aspect was classified (north facing or south facing) from 1:25000 Swisstopo pixel maps (Bundesamt für Landestopographie, Bern, Switzerland). Based on this information, 11 groups of adjacent stands were selected that contained all factor combinations of tree density (high vs. low) and aspect (north vs. south) in close proximity. The classification was validated in the field, and stands were surveyed for the presence of appropriate receptor trees. From all sycamore maple (Acer pseudoplatanus) trees exceeding a diameter at breast height of $15 \mathrm{~cm}$, one tree per treatment was selected as a receptor tree. We transplanted lichen propagules to 44 trees within the 11 selected blocks, each under four treatment combinations: north-high, north-low, southhigh, and south-low. In addition, 11 freestanding trees also received transplants. Note that $L$. pulmonaria does not occur on freestanding trees in the wooded pastures of the study area.

Establishment of soredia transplants.-To avoid an effect of local adaptation of some thalli, but not others, L. pulmonaria soredia were collected from a forest stand at a distance of $3 \mathrm{~km}$ from the nearest transplantation site, pooling soredia from about 50 thalli collected on different trees. Material from high-light- and low-lightadapted thalli was collected separately, and high-lightadapted soredia were applied to stands of low tree density, whereas low-light-adapted soredia were applied to stands of high tree density following Sillett et al. (2000), to minimize the effect of light adaptation which we were not interested in. Transplants were established on 2-5 July 2002. Pieces of cotton gauze used for medical purposes were attached to the bark with aluminum staples. Aluminum is considered preferable to zinc alloy as it exhibits little corrosion (Zoller et al. 2000). Soredia transplants were established on two substrates (gauze vs. bark), exposed toward the north on the stem. At a stem height of $1.4 \mathrm{~m}$, one gauze piece of $9 \mathrm{~cm}^{2}$ was attached, divided into nine $1-\mathrm{cm}^{2}$ quadrates. On each of the quadrates, deionized water containing L. pulmonaria soredia was applied using a paintbrush. At a distance of $5 \mathrm{~cm}$ upstem from the gauze piece, soredia were transferred to a $9-\mathrm{cm}^{2}$ bark area previously weeded from bryophytes and macrolichens using the same procedure. Using this application procedure, the absolute number of soredia applied to each quadrate may have varied, but we applied several hundred soredia to each quadrate. Re-inoculation was performed once in late October 2002. Fifteen months after first inoculation (i.e., after two vegetation periods), the number of thalli on each of the nine bark and gauze quadrates per tree was counted. Each thallus was counted up to 25 , and then, classes of $50,75,100,150$, 
TABLE 1. Sensitivity of the real-time PCR assay of the fungal ITS (internal transcribed spacer) region in Lobaria pulmonaria.

\begin{tabular}{lcccc}
\hline \hline No. soredia & 0 positives & 1 positive & 2 positives & 3 positives \\
\hline 1 soredium & 1 & 0 & 3 & 7 \\
3 soredia & 0 & 0 & 6 & 6 \\
10 soredia & 0 & 0 & 2 & 10
\end{tabular}

Notes: DNA extracted from 1, 3, and 10 soredia was amplified with three real-time PCR reactions each: 0 positives indicates no positive real-time PCR reactions; 1 positive indicates one positive real-time PCR reaction out of three; 2 positives indicates two out of three real-time PCR reactions positive; and 3 positives indicates that all real-time PCR reactions were positive.

200, 250,300, and 350 were used. Class midpoints were used in further analyses.

\section{Data analysis}

We performed analysis of variance (ANOVA) of distance from source tree and direction, both fixed factors, on the frequency of samples containing the same ITS allele as the single, isolated tree. We also added the factor snow trap position (protruding or at the snow level) into the ANOVA model, but, as this factor was not significant, it was excluded from further analyses (results not shown). ANOVA was performed using the "aov" function in R (R Development Core Team 2004).

As the distant sources were multiple and unknown, we could not fit a mixed dispersal model including an exponential or Weibull term for long-distance dispersal. Long-distance dispersal was represented by an intercept model fitted to the positive samples containing an ITS allele different from that of the point source. To calibrate the local dispersal kernel, an exponential model $f(d)=a \cdot \exp (-a d)$ was fitted to the number of positive samples in 10 buckets per distance class, pooled over the four directional transects, where $a$ is the dispersal parameter estimate and $d$ is the distance. The model was fitted with Poisson regression using the function "glm" in R (R Development Core Team 2004). An adjusted bootstrap percentile confidence interval for $a$ was estimated using ordinary nonparametric bootstrap with random x resampling (Fox 1997) as implemented in the functions "boot" and "boot.ci" of the R library "boot" by Davison and Hinkley (1997). Because the proportional area sampled at each distance decreases with the distance from the source, we adjusted for circular area in the calculation of the mean dispersal distance (Griffith and Forseth 2002). The probability density function of the dispersal distance of each propagule was defined by $g(d)=f(d) \cdot a \cdot d$, and the mean dispersal distance was derived as $\bar{d}=\Sigma_{d=1}^{1000} g(d) \cdot d$, taking into account the bootstrap confidence interval for $a$.

For each allele of five microsatellite loci found across the snow samples, we determined the minimum Euclidean distance to a known occurrence of the same allele based on the dataset by Werth et al. (2006).
To test for differences in establishment of soredia between four treatments and two substrates, we performed a split-plot ANOVA of the effect of treatment and substrate on the log-transformed number of established young thalli per tree (response variable), using the groups of adjacent forest stands containing all four treatment combinations as blocks. As the freestanding maple trees occurred scattered throughout the study area and were not close to the forest stands ("block") that received transplants, this treatment group had to be omitted from analysis of variance. We also computed the variance in number of established soredia among $1-\mathrm{cm}^{2}$ quadrates on gauze and bark substrate. Furthermore, we did a $t$ test to see if the number of established young thalli was higher on trees that were already colonized by L. pulmonaria than on trees that had not been colonized prior to the experiment. This $t$ test that we performed for the pooled number of established young thalli on bark and gauze substrates using R did not assume equality of variances.

\section{Results}

Both the real-time PCR and the microsatellite approach were specific and sensitive to L. pulmonaria. The real-time PCR approach enabled the reliable detection of as little as a single soredium, and only 1 out of 11 DNA extracts containing a single $L$. pulmonaria soredium were found to be negative in three replicate real-time PCR amplification reactions (Table 1). When we genotyped extracts with 3 or 10 soredia, at least two PCR reactions were positive, indicating that three replicates were sufficient to detect small amounts of material. The filter paper extracts did not contain any PCR inhibitors, for they yielded positive reactions with both real-time PCR and microsatellite analysis (10 samples tested, all positive). Contaminations during the 1344 DNA extractions did not bias the analyses in this study, as only 1 out of 70 negative controls was found to be positive. However, 5 out of 77 blind samples were positive, indicating that during a few filterings, material had been transferred to the next sample. None of the other lichen species tested yielded amplification products with any of the microsatellite primers or realtime PCR, with two exceptions ( $L$. linita, a clearly shorter allele in $L P u 09$; and $U$. hirta, an allele not fitting into the allele size classes in $L P u 09$ ).

\section{Landscape approach}

Based on the ITS and microsatellite approach, we detected positive snow samples in only eight 1-ha plots in the landscape approach (24 plots investigated; Fig. 1). In one of these eight plots, microsatellite alleles were detected in two microsatellite loci that were identical to the microsatellite alleles found in L. pulmonaria thalli from the plot by a previous study (Werth et al. 2006). In three out of the eight plots containing three or more trees colonized by $L$. pulmonaria, positives were found. We also detected samples positive for L. pulmonaria in 


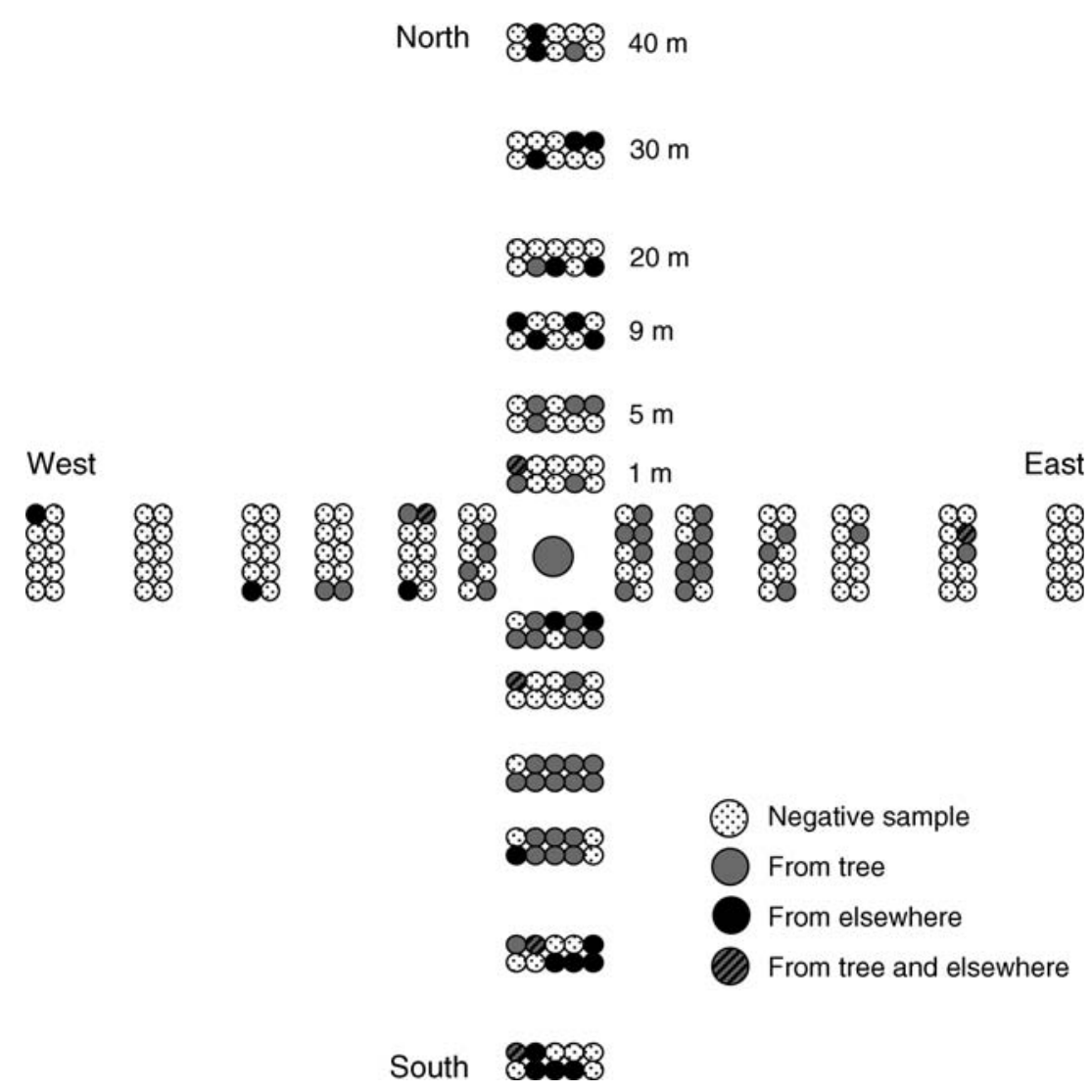

FIG. 2. Point source approach to dispersal of Lobaria pulmonaria, inferred from genotyping of the fungal ITS region. The large circle in the center indicates the position of the single isolated tree colonized by L. pulmonaria. Each small circle indicates the geographic location of a bucket used to sample snow. Key to symbols: dotted, no diaspores of L. pulmonaria detected; gray, ITS allele of the source tree; black, ITS allele from another source; hatched, both ITS alleles found.

three out of eight 1 -ha plots not colonized by $L$. pulmonaria, and in two out of eight 1-ha plots from the open area. From the two open-area plots in which we found positive snow samples, the closest known $L$. pulmonaria tree was located at distances of $150 \mathrm{~m}$ and $180 \mathrm{~m}$, respectively (Fig. 1).

\section{Point source approach}

From the 61 samples sharing an ITS allele with the source tree (Fig. 2), 17 also contained SSR alleles different from those of the source tree, thus suggesting dispersal from another source. However, most microsatellite alleles detected in the snow samples were identical to those that occurred on the isolated source tree. Comparing the microsatellite alleles found in the snow traps with those found in thalli of the study area by a previous study (Werth et al. 2006), the distance to the closest occurrences of five microsatellite alleles were $188,375,393,1372$, and $1800 \mathrm{~m}$, while four microsatellite alleles were new for the study area. Fitting an exponential function to the number of samples containing the ITS allele from the source tree per distance class resulted in an estimated dispersal parameter of $a=0.052$ with a bias-corrected bootstrap interval of $0.038,0.064$
(Fig. 3). The corresponding mean dispersal distance, accounting for circular area, was estimated as $38.4 \mathrm{~m}$, with a confidence interval of $31.1,52.2$. However, there was also strong evidence for substantial dispersal from sources other than the point source (hereafter called "global dispersal"; Fig. 2). The average number of positive samples containing the non-local ITS allele over all distance classes equaled the number of positive samples for the local allele expected and observed at 20 $\mathrm{m}$ from the point source. In the point source approach, ANOVA showed significant effects of distance and direction from source tree on the number of positive snow samples containing the local ITS allele, and a significant interaction of the distance and direction (Table 2), implying that dispersal of propagules of $L$. pulmonaria was anisotropic.

\section{Transplantation experiment}

We found no significant effect of the treatment (combination of high/low tree density and north/south exposure) on the log-transformed number of established young thalli (response variable), but a significant block effect (Table 3, Fig. 4). There was also a significant effect of substrate on the number of established young thalli, 


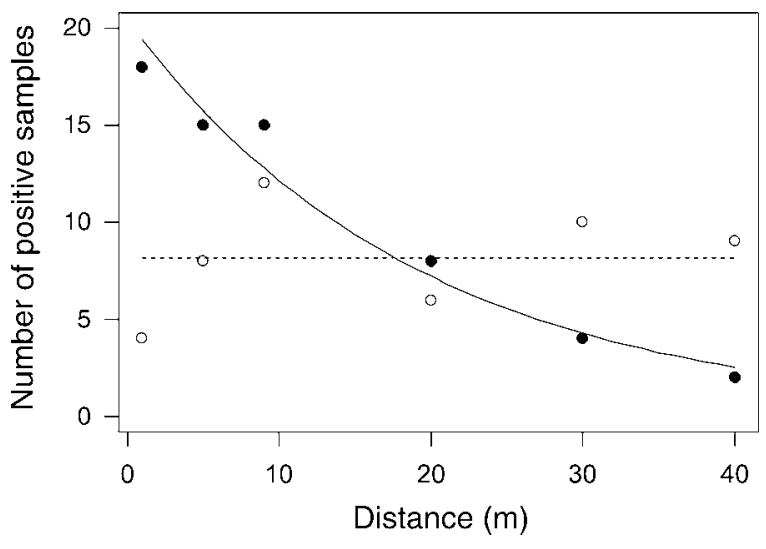

FIG. 3. Dispersal kernel of Lobaria pulmonaria estimated from the point source approach. Symbols denote the observed number of samples containing the ITS allele from the source tree (solid circles) or from elsewhere (open circles) for each distance from the source, pooled over all four directions $\left(N_{d}=\right.$ 40 for each distance $d$ ). The distribution of the local allele was fitted with the exponential function $(y=\exp (3.02-0.052 d)$; solid line); the distribution of the non-local allele was fitted with an intercept model $(y=8.17$; dotted line).

i.e., lower establishment on bark than on artificial gauze substrate, but no significant interaction between treatment and substrate (Table 3, Fig. 4). The variance within all treatment groups was high. It is notable that soredia transplanted to freestanding trees did not perform much worse than soredia transplanted to forest stands: There were $160.4 \pm 33.0$ (mean $\pm \mathrm{SE}$ ) established young thalli on bark and gauze substrate overall for freestanding trees, whereas there were $181.0 \pm 56.6$ established young thalli on bark and gauze substrate overall for forest sites. The variance in the number of established young thalli was high among $1-\mathrm{cm}^{2}$ quadrates (minimum, mean, and maximum variance on bark $=0,246,4392$, respectively; and on gauze $=0,1060,10112$, respectively). Even though the absolute number of established young thalli was larger on trees that were already colonized by $L$. pulmonaria prior to the experiment, soredia did not perform better on pre-colonized trees than on uncolonized trees (one-sided $t$ test, $N=55, t=0.498, \mathrm{df}=13.3, P$ $=0.313$, mean for uncolonized $=330.8$, mean for colonized $=407.7$ ).

\section{Discussion}

The main objectives of this study were to assess the importance of dispersal vs. establishment limitation, and to explore under which conditions transplanted soredia of L. pulmonaria establish best.

\section{Dispersal range and anisotropy}

A notably large amount of L. pulmonaria diaspores was detected from sources other than the isolated sycamore tree investigated, demonstrating that dispersal of sexual or clonal propagules over larger distances (i.e., $\geq 200 \mathrm{~m}$ ) may be a rather common phenomenon in $L$. pulmonaria. Simulation modeling of forest recolonization by $L$. pulmonaria demonstrated that a significant influx of sexual or clonal diaspores was necessary to explain its abundance and genotype diversity in disturbed areas (Wagner et al., in press). Variogram modeling of gene diversity and genotype diversity indicated a different dispersal function for clonal and sexual propagules (Werth et al. 2006). It is notable that the high amount of dispersal over larger distances is at variance with a dispersal estimate from a study relying on the spatial distribution of the lichen (Öckinger et al. 2005), which records a maximum dispersal distance of $75 \mathrm{~m}$ for L. pulmonaria. Shorter dispersal distances are indeed expected in established thalli as compared to the dispersed propagules detected in our study, as a large amount of dispersed propagules may never establish to young thalli for various mortality reasons, e.g., because they did not reach suitable habitat.

The result of significant dispersal over larger distances was also supported by the data on landscape-level dispersal. We detected L. pulmonaria diaspores both in plots situated in an open large pasture and in forested plots within which the species did not occur. We found about as many positive snow samples in colonized forest stands as in uncolonized stands or unforested areas. However, the number of positive samples detected was low compared to results from the point source approach. As sampling for the landscape approach occurred in late March when the snow had melted and frozen repeatedly, we reckon that the samples were already rather degraded, so that PCR reactions were inhibited due to poor DNA quality. The samples from the landscape approach also contained large amounts of fine litter and dust particles, which may have contained PCR inhibitors. In future studies of lichen dispersal employing snow samples, we thus recommend that snow should either be collected in snow traps exposed for a short time period or from a fresh snow layer.

Dispersal of propagules of L. pulmonaria around a point source was anisotropic, a finding corroborating the results of Walser et al. (2001). Whether or not an anisotropic pattern is found may, however, strongly depend on the length of the time period during which snow traps are exposed, as the wind direction is unlikely

TABLE 2. Point source approach to studying dispersal in Lobaria pulmonaria, inferred from molecular analyses of snow samples collected in the Swiss Jura Mountains.

\begin{tabular}{lrrccr}
\hline \hline \multicolumn{1}{c}{ Source } & ss & df & MS & $F$ & \multicolumn{1}{c}{$P$} \\
\hline Distance & 27.4 & 5 & 5.5 & 9.7 & $<0.0001$ \\
Direction & 14.6 & 3 & 4.9 & 8.6 & 0.0005 \\
Distance $\times$ direction & 36.6 & 15 & 2.4 & 4.3 & 0.0007 \\
Error & 0.6 & 23 & 0.6 & & \\
\hline
\end{tabular}

Notes: The table shows results from ANOVA of distance (fixed factor) and transect direction (fixed factor) on the frequency of positive snow samples. The table relies on the samples containing the same ITS allele, which was found in $L$. pulmonaria from a sycamore tree isolated within a spruce forest (point source approach). 
TABLE 3. Result of split-plot ANOVA of the effect of treatment (combination of high/low tree density and north/ south exposure) and transplantation substrate (gauze vs. bark) on the log-transformed number of established juveniles in Lobaria pulmonaria 15 months after setting up the experiment.

\begin{tabular}{lrrrrr}
\hline \hline \multicolumn{1}{c}{ Source } & ss & df & MS & $F$ & $P$ \\
\hline Between & & & & & \\
$\quad$ Block & 21.76 & 10 & 2.18 & 4.64 & 0.010 \\
$\quad$ Treatment & 0.21 & 3 & 0.07 & 0.14 & 0.930 \\
$\quad$ Error & 14.35 & 30 & 0.47 & & \\
Within & & & & & \\
$\quad$ Substrate & 9.93 & 1 & 9.93 & 52.62 & $<0.001$ \\
$\quad$ Treatment $\times$ substrate & 0.19 & 3 & 0.06 & 0.34 & 0.794 \\
$\quad$ Error & 7.55 & 40 & 0.19 & & \\
\hline
\end{tabular}

to be constant. Most likely, with increasing time, most or all snow traps will eventually contain propagules of L. pulmonaria.

\section{Dispersal vs. establishment limitation}

The substantial amount of long-distance dispersal detected for L. pulmonaria emphasizes that care has to be taken when species are classified as dispersal limited, particularly if such an argumentation is based on studies of already established individuals (Walser 2004, Öckinger et al. 2005) or of juvenile establishment from artificially sown propagules (Sillett et al. 2000, Hilmo and Såstad 2001, Walser 2004). A previous study has shown that 130 years after a stand-replacing disturbance, L. pulmonaria managed to colonize the disturbed sites (24 ha) and had developed large population sizes, although genetic diversity of the disturbed sites was still lower than in adjacent sites not affected by the disturbance (Kalwij et al. 2005, Werth et al. 2006). Thus, at the spatial scale of our study area, the putatively dispersal-limited L. pulmonaria (Scheidegger 1995, Zoller et al. 1999) is unlikely to be dispersal limited, a finding which is also corroborated by high amounts of past gene flow and weak genetic differentiation among areas within the study landscape (S. Werth, unpublished data).

Öckinger et al. (2005) concluded that habitat quality may be an important factor for the local distribution of L. pulmonaria at small spatial scales. Our findings are slightly contradictory to this conclusion; at least, neither tree density nor forest stand aspect seemed to be a major determinant for the establishment success of L. pulmonaria. However, the reason for this might be that we transplanted all propagules to the north side of the trees, which probably excluded major microclimatic variation. We found higher establishment of $L$. pulmonaria on artificial gauze substrate than on bark. This might be partly explained by diaspores being washed downstem from the bark quadrates into the gauze. Also, other studies have shown that gauze is a very suitable growth substrate for lichen diaspores, leading to high numbers of established young thalli (Zoller et al. 2000). A part of the diaspores that we observed on the bark and gauze substrate may well have been transported to the transplantation sites from nearby propagule sources, but this does not explain, e.g., the diverging numbers of established young thalli between gauze and bark substrates. A striking result is that the number of established young thalli on trees pre-colonized by $L$. pulmonaria was not significantly different from that of uncolonized trees. On pre-colonized trees, one might have expected particularly high numbers of diaspores to be wind-dispersed to other parts of the stem, or to be washed downstem with run-off water and to establish on the area that had received transplanted diaspores, but apparently, this was not the case. It seems even less likely that propagule sources further away may have influenced the number of established young thalli significantly. Note that this does not mean that no
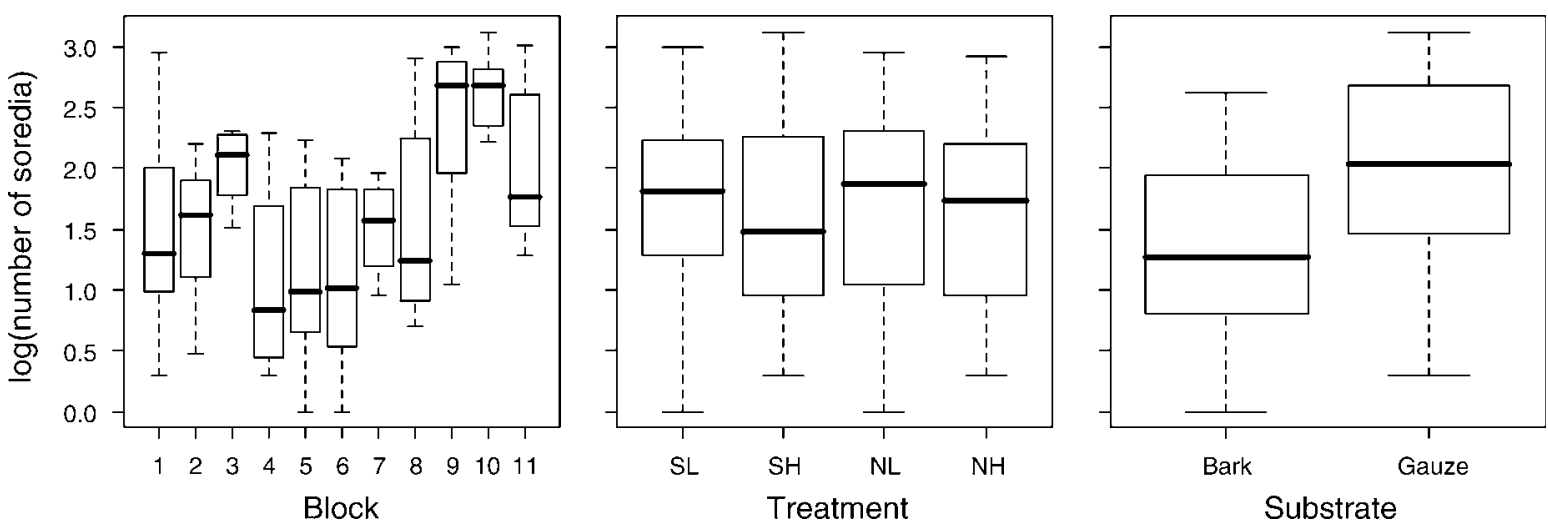

FIG. 4. Box plots showing the number of log-transformed established soredia in Lobaria pulmonaria transplanted in the Swiss study site in relation to block (blocks $=11$ sites, each containing four trees onto which soredia of L. pulmonaria were transplanted), transplantation treatment (NH, north exposed, high tree density; NL, north exposed, low tree density; SH, south exposed, high tree density; SL, south exposed, low tree density), and transplantation substrate (bark or gauze). For further information, see Methods; Quantifying establishing limitation. 
external diaspores reached the surfaces we transplanted to, but rather that an insignificant number of diaspores may have established. Furthermore, we observed few young thalli adjacent to our transplantation area.

For tripartite lichens such as L. pulmonaria (Rikkinen et al. 2002), a major determinant of diverging growth of propagules among trees and sites may be the availability of cyanobacteria. The cyanobacteria of the genus Nostoc associated with $L$. pulmonaria belong to different strains than known in free-living cyanobacteria (Rikkinen et al. 2002). Juveniles of $L$. pulmonaria need to find and incorporate cyanobacteria (C. Cornejo and C. Scheidegger, unpublished data) in the thallus. As soredia of $L$. pulmonaria only contain the mycobiont and the green algal photobiont, local unavailability of cyanobacteria could be the major determinant limiting establishment of L. pulmonaria.

Establishment limitation of lichens associated with old forests has been examined in experimental studies with the result that establishment is generally not a limiting factor for recruitment of old-forest lichens in young forests (Sillett et al. 2000, Hilmo and Såstad 2001). However, one may not be able to predict the longterm persistence of lichen transplants from short-term studies. Competition by fast-growing lichens and bryophytes is likely to play a major role, and it is quite likely that transplanted propagules of slow-growing species such as those of the genus Lobaria may be outcompeted within a few years (Antoine and McCune 2004). Even after only two vegetation periods, initial stages of bryophytes and fast-growing lichens were visible on some of the experimental gauze and bark substrates. Like most other short-term studies involving experimental transplantation of lichen propagules, the results of our transplantation experiment do not allow conclusions on the long-term survival of the established young thalli.

What our results have clearly shown, however, is an enormous variance in growth of propagules among sites: Some microspots were more favorable for establishment than others. Thus, it is probably not dispersal limitation that hinders colonization in L. pulmonaria, but ecological factors at the stand level resulting in establishment limitation. Our study demonstrates that care has to be taken to disentangle dispersal limitation from establishment limitation.

\section{ACKNOWLEDGMENTS}

Fabienne Föry and Marcus Hofer kindly helped with the filtering and preparation of snow samples and with DNA extraction, and Svetlana Chabanenko helped during the fieldwork. Marco Gut (Applied Biosystems, Rotkreuz, Switzerland) made helpful suggestions for the design of the real-time PCR assay. We thank two anonymous reviewers for their valuable comments on the manuscript. We thank Swisstopo for providing color infrared aerial photographs to Jesse M. Kalwij. This research is part of a project funded by the Swiss National Science Foundation (SNF) under NCCR Plant Survival.

\section{Literature Cited}

Antoine, M. E., and B. McCune. 2004. Contrasting fundamental and realized ecological niches with epiphytic lichen transplants in an old-growth Pseudotsuga forest. Bryologist 107:163-172.

Aylor, D. E. 2003. Spread of plant disease on a continental scale: role of aerial dispersal of pathogens. Ecology 84:19891997.

Belisle, M., and A. Desrochers. 2002. Gap-crossing decisions by forest birds: an empirical basis for parameterizing spatiallyexplicit, individual-based models. Landscape Ecology 17: 219-231.

Bohonak, A. J. 1999. Dispersal, gene flow, and population structure. Quarterly Review of Biology 74:21-45.

Bridle, J. R., S. J. E. Baird, and R. K. Butlin. 2001. Spatial structure and habitat variation in a grasshopper hybrid zone. Evolution 55:1832-1843.

Bullock, J. M., and R. T. Clarke. 2000. Long-distance seed dispersal by wind: measuring and modelling the tail of the curve. Oecologia 124:506-521.

Clark, J. S., M. Lewis, J. S. McLachlan, and J. HilleRisLambers. 2003. Estimating population spread: What can we forecast and how well? Ecology 84:1979-1988.

Clobert, J., E. Danchin, A. A. Dhondt, and J. D. Nichols. 2001. Dispersal. Oxford University Press, Oxford, UK.

Davison, A. C., and D. V. Hinkley. 1997. Bootstrap methods and their application. Cambridge University Press, Cambridge, UK.

Dyer, R. J., R. D. Westfall, V. L. Sork, and P. E. Smouse. 2004. Two-generation analysis of pollen flow across a landscape: a stepwise approach for extracting factors contributing to pollen structure. Heredity 92:204-211.

Fischer, J., and D. B. Lindenmayer. 2002. The conservation value of paddock trees for birds in a variegated landscape in southern New South Wales. 2. Paddock trees as stepping stones. Biodiversity and Conservation 11:833-849.

Fox, J. 1997. Applied regression analysis, linear models, and related methods. Sage, Thousand Oaks, California, USA.

Gauslaa, Y., and K. A. Solhaug. 1999. High-light damage in air-dry thalli of the old forest lichen Lobaria pulmonaria: interactions of irradiance, exposure duration and high temperature. Journal of Experimental Botany 50:697-705.

Gilbert, B., and M. J. Lechowicz. 2004. Neutrality, niches, and dispersal in a temperate forest understory. Proceedings of the National Academy of Sciences (USA) 101:7651-7656.

Griffith, A. B., and I. N. Forseth. 2002. Primary and secondary seed dispersal of a rare, tidal wetland annual, Aeschynomene virginica. Wetlands 22:696-704.

Hall, J. S., J. J. McKenna, P. M. S. Ashton, and T. G. Gregoire. 2004. Habitat characterizations underestimate the role of edaphic factors controlling the distribution of Entandrophragma. Ecology 85:2171-2183.

Hanski, I., and O. Gaggiotti. 2004. Ecology, genetics, and evolution of metapopulations. Elsevier Academic Press, London, UK.

Haynes, K. J., and J. T. Cronin. 2004. Confounding of patch quality and matrix effects in herbivore movement studies. Landscape Ecology 19:119-124.

Higgins, S. I., R. Nathan, and M. L. Cain. 2003. Are longdistance dispersal events in plants usually caused by nonstandard means of dispersal? Ecology 84:1945-1956.

Hilmo, O., and S. M. Såstad. 2001. Colonization of old-forest lichens in a young and an old boreal Picea abies forest: an experimental approach. Biological Conservation 102:251259.

Kalwij, J. M., H. H. Wagner, and C. Scheidegger. 2005. Effects of stand-level disturbances on the spatial distribution of a lichen indicator. Ecological Applications 15:2015-2024.

Keitt, T. H., D. L. Urban, and B. T. Milne. 1997. Detecting critical scales in fragmented landscapes. Conservation 
Ecology (online) 1:4. 〈http://www.consecol.org/voll/iss 1/ $\operatorname{art} 4\rangle$

Kirchhofer, W. 1995. Klimaatlas der Schweiz. Bundesamt für Landestopographie, Wabern-Bern, Switzerland.

Landeshydrologie und -geologie. 1992. Hydrologischer Atlas der Schweiz. Bundesamt für Landestopographie, WabernBern, Switzerland.

Levin, D. A. 1995. Metapopulations: an arena for local speciation. Journal of Evolutionary Biology 8:635-644.

Levin, S. A., H. C. Müller-Landau, R. Nathan, and J. Chave. 2003. The ecology and evolution of seed dispersal: a theoretical perspective. Annual Review of Ecology Evolution and Systematics 34:575-604.

Nathan, R., and H. C. Müller-Landau. 2000. Spatial patterns of seed dispersal, their determinants and consequences for recruitment. Trends in Ecology and Evolution 15:278-285.

Nathan, R., G. Perry, J. T. Cronin, A. E. Strand, and M. L. Cain. 2003. Methods for estimating long-distance dispersal. Oikos 103:261-273.

Nathan, R., U. N. Safriel, and I. Noy-Meir. 2001. Field validation and sensitivity analysis of a mechanistic model for tree seed dispersal by wind. Ecology 82:374-388.

Neigel, J. E. 2002. Is $F_{\mathrm{ST}}$ obsolete? Conservation Genetics 3 : 167-173.

Öckinger, E., M. Niklasson, and S. G. Nilsson. 2005. Is local distribution of the epiphytic lichen Lobaria pulmonaria limited by dispersal capacity or habitat quality? Biodiversity and Conservation 14:759-773.

Ozinga, W. A., J. H. J. Schaminee, R. M. Bekker, S. Bonn, P. Poschlod, O. Tackenberg, J. Bakker, and J. M. van Groenendael. 2005. Predictability of plant species composition from environmental conditions is constrained by dispersal limitation. Oikos 108:555-561.

Paradis, E., S. E. Baille, and W. J. Sutherland. 2002. Modeling large-scale dispersal distances. Ecological Modelling 151: 279-292.

Parker, M., and R. Mac Nally. 2002. Habitat loss and the habitat fragmentation threshold: an experimental evaluation of impacts on richness and total abundances using grassland invertebrates. Biological Conservation 105:217-229.

R Development Core Team. 2004. R: a language and environment for statistical computing. R Foundation for Statistical Computing, Vienna, Austria. /http://www.R-project.org/ index.html

Rikkinen, J., I. Oksanen, and K. Lohtander. 2002. Lichen guilds share related cyanobacterial symbionts. Science 297: 357.

Rolstad, J., I. Gjerde, K. O. Storaunet, and E. Rolstad. 2001. Epiphytic lichens in Norwegian coastal spruce forest: historic logging and present forest structure. Ecological Applications 11:421-436.

Rose, F. 1992. Temperate forest management: its effects on bryophyte and lichen floras and habitats. Pages 211-233 in J. W. Bates and A. M. Farmer, editors. Bryophytes and lichens in a changing environment. Clarendon, Oxford, UK.

Scheidegger, C. 1995. Early development of transplanted isidioid soredia of Lobaria pulmonaria in an endangered population. Lichenologist 27:361-374.

Scheidegger, C., U. Groner, C. Keller, and S. Stofer. 2002. Biodiversity assessment tools - lichens. Pages 359-365 in P. L. Nimis, C. Scheidegger, and P. A. Wolseley, editors. Monitoring with lichens: monitoring lichens. Kluwer, Dordrecht, The Netherlands.

Sillett, S. C., B. McCune, J. E. Peck, T. R. Rambo, and A. Ruchty. 2000. Dispersal limitations of epiphytic lichens result in species dependent on old-growth forests. Ecological Applications 10:789-799.
Snäll, T., J. Ehrlen, and H. Rydin. 2005a. Colonizationextinction dynamics of an epiphyte metapopulation in a dynamic landscape. Ecology 86:106-115.

Snäll, T., J. Pennanen, L. Kivistö, and I. Hanski. $2005 b$. Modelling epiphyte metapopulation dynamics in a dynamic forest landscape. Oikos 109:209-222.

Sork, V. L., J. Nasin, D. R. Campbell, and J. F. Fernandez. 1999. Landscape approaches to historical and contemporary gene flow in plants. Trends in Ecology and Evolution 14:219224.

Svenning, J. C., D. A. Kinner, R. F. Stallard, B. M. J. Engelbrecht, and S. J. Wright. 2004. Ecological determinism in plant community structure across a tropical forest landscape. Ecology 85:2526-2538.

Szacki, J. 1999. Spatially structured populations: how much do they match the classic metapopulation concept? Landscape Ecology 14:369-379.

Tischendorf, L., D. J. Bender, and L. Fahrig. 2003. Evaluation of patch isolation metrics in mosaic landscapes for specialist vs. generalist dispersers. Landscape Ecology 18:41-50.

Travis, J. M. J., and D. R. French. 2000. Dispersal functions and spatial models: expanding our dispersal toolbox. Ecology Letters 3:163-165.

Vittoz, P. 1998. Flore et végétation du Parc jurassien vaudois: typologie, écologie et dynamique des milieux. Dissertation. University of Lausanne, Lausanne, Switzerland.

Wagner, H. H., S. Werth, J. M. Kalwij, and C. Scheidegger. In press. Modeling forest recolonization by an epiphytic lichen using a landscape genetic approach. Landscape Ecology.

Walser, J. C. 2004. Molecular evidence for limited dispersal of vegetative propagules in the epiphytic lichen Lobaria pulmonaria. American Journal of Botany 91:1273-1276.

Walser, J. C., C. Sperisen, M. Soliva, and C. Scheidegger. 2003. Fungus-specific microsatellite of lichens: application for the assessment of genetic variation on different spatial scales in Lobaria pulmonaria. Fungal Genetics and Biology 40:72-82.

Walser, J. C., S. Zoller, U. Büchler, and C. Scheidegger. 2001. Species-specific detection of Lobaria pulmonaria (lichenized ascomycete) diaspores in litter samples trapped in snow cover. Molecular Ecology 10:2129-2138.

Werth, S., H. H. Wagner, R. Holderegger, J. M. Kalwij, and C. Scheidegger. 2006. Effect of disturbances on the genetic diversity of an old-forest associated lichen. Molecular Ecology 15:911-921.

Wiens, J. A., N. C. Stenseth, B. Vanhorne, and R. A. Ims. 1993. Ecological mechanisms and landscape ecology. Oikos 66: 369-380.

With, K. A., S. J. Cadaret, and C. Davis. 1999. Movement responses to patch structure in experimental fractal landscapes. Ecology 80:1340-1353.

With, K. A., and T. O. Crist. 1995. Critical thresholds in species responses to landscape structure. Ecology 76:2446-2459.

With, K. A., and A. W. King. 1999. Dispersal success on fractal landscapes: a consequence of lacunarity thresholds. Landscape Ecology 14:73-82.

Yu, D. W., H. B. Wilson, M. E. Frederickson, W. Palomino, R. De la Colina, D. P. Edwards, and A. A. Balareso. 2004. Experimental demonstration of species coexistence enabled by dispersal limitation. Journal of Animal Ecology 73:11021114.

Zoller, S., B. Frey, and C. Scheidegger. 2000. Juvenile development and diaspore survival in the threatened epiphytic lichen species Sticta fuliginosa, Leptogium saturninum and Menegazzia terebrata: Conclusions for in situ conservation. Plant Biology 2:496-504.

Zoller, S., F. Lutzoni, and C. Scheidegger. 1999. Genetic variation within and among populations of the threatened lichen Lobaria pulmonaria in Switzerland and implications for its conservation. Molecular Ecology 8:2049-2059. 